\title{
Propofol inhibits lung cancer cell viability and induces cell apoptosis by upregulating microRNA-486 expression
}

\author{
N. Yang ${ }^{1}$, Y. Liang ${ }^{2}$, P. Yang ${ }^{1}$, T. Yang ${ }^{1}$ and L. Jiang ${ }^{1}$ \\ ${ }^{1}$ Department of Anesthesiology, The First Affiliated Hospital of Wenzhou Medical University, Wenzhou, Zhejiang Province, China \\ ${ }^{2}$ Department of Pediatric Intensive Care Unit, The Second Affiliated Hospital of Wenzhou Medical University, \\ Wenzhou, Zhejiang Province, China
}

\begin{abstract}
Propofol is a frequently used intravenous anesthetic agent. Recent studies show that propofol exerts a number of nonanesthetic effects. The present study aimed to investigate the effects of propofol on lung cancer cell lines $\mathrm{H} 1299$ and $\mathrm{H} 1792$ and functional role of microRNA (miR)-486 in these effects. H1299 and/or H1792 cells were treated with or without propofol and transfected or not with miR-486 inhibitor, and then cell viability and apoptosis were analyzed by 3-(4,5-dimethylthiazol-2-yl)-2,5diphenyltetrazolium bromide (MTT) and flow cytometry. The expression of miR-486 was determined by quantitative real-time polymerase chain reaction (qRT-PCR) with or without propofol treatment. Western blot was performed to analyze the protein expression of Forkhead box, class O (FOXO) 1 and 3, Bcl-2 interacting mediator of cell death (Bim), and pro- and activated caspases-3. Results showed that propofol significantly increased the miR-486 levels in both H1299 and H1792 cells compared to untreated cells in a dose-dependent manner $(\mathrm{P}<0.05$ or $\mathrm{P}<0.01)$. Propofol statistically decreased cell viability but increased the percentages of apoptotic cells and protein expressions of FOXO1, FOXO3, Bim, and pro- and activated caspases-3; however, miR-486 inhibitor reversed the effects of propofol on cell viability, apoptosis, and protein expression $(\mathrm{P}<0.05$ or $\mathrm{P}<0.01$ ). In conclusion, propofol might be an ideal anesthetic for lung cancer surgery by effectively inhibiting lung cancer cell viability and inducing cell apoptosis. Modulation of miR-486 might contribute to the anti-tumor activity of propofol.
\end{abstract}

Key words: Propofol; Lung cancer; Cell viability; Cell apoptosis; microRNA-486

\section{Introduction}

Lung cancer is the leading cause of cancer-related death in both men and women worldwide (1), accounting for approximately $28 \%$ of all cancer deaths (2). In 2012, more than 1.8 million newly diagnosed lung cancer cases and about 1.6 million deaths were estimated (3). It has been reported that more than $1 / 3$ of all new lung cancer cases were diagnosed in China, leading to a major burden for both patients and their families (4). Moreover, the incidence of lung cancer has been reported to be increasing in China (4). Although tremendous advance has been made in recent years in prevention and treatment of lung cancer, the mortality is still very high because of the unclear molecular pathogenesis, with a 5-year survival rate of less than $16 \%$ for patients with advanced stage (5).

MicroRNAs (miRNAs) are a class of endogenous, single-stranded, small, non-coding RNAs that negatively regulate gene expression at the post-transcriptional level by mainly binding to $3^{\prime}$-untranslated region (UTR) of target mRNAs, leading to mRNA degradation or translational inhibition (6). It has been well acknowledged that miRNAs play an essential role in various biological processes such as cell proliferation, apoptosis, differentiation, migration and invasion (7). An increasing number of studies have suggested that miRNAs are involved in the pathophysiology of cancers, and may provide a new insight into cancer treatment $(8,9)$. Aberrant expression of miRNAs have been well described in lung cancer $(10,11)$. Among miRNAs, miR-486 has been confirmed as a novel tumor-suppressor miRNA in many cancers including lung cancer $(12,13)$. Therefore, upregulation of miR-486 expression might be a potential treatment for lung cancer.

Propofol is a frequently used intravenous anesthetic agent. Accumulating evidence suggests that propofol has a number of non-anesthetic effects (14). Recently, propofol was reported to show many potential anticancer properties, such as inhibition of proliferation, adhesion, and metastasis of cancer cells and induction of cell apoptosis (15-17). Hence, propofol is considered a better

Correspondence: L. Jiang: <jiangliuming4759@126.com>

Received August 29, 2016 | Accepted September 3, 2016 
anesthetic agent than other anesthetics during cancer surgery (18). However, little information is available about the antitumor activity of propofol in lung cancer cells. Therefore, the present study aimed to explore the effects of propofol on the biological behavior of lung cancer cells, as well as the related underlying molecular mechanisms.

\section{Material and Methods}

\section{Cell culture}

Lung cancer cell lines $\mathrm{H} 1299$ and $\mathrm{H} 1792$ were obtained from the American Type Culture Collection (ATCC, USA). The cells were cultured in Roswell Parker Memorial Institute (RPMI)-1640 medium (Sigma-Aldrich, USA) supplemented with $10 \%$ fetal bovine serum (FBS, Gibco, USA) $100 \mathrm{U} / \mathrm{mL}$ penicillin (Gbico), and $100 \mathrm{mg} / \mathrm{L}$ streptomycin (Gbico) at $37^{\circ} \mathrm{C}$ in a humidified atmosphere with $5 \% \mathrm{CO}_{2}$.

\section{Cell treatment and transfection}

For cell treatment, cells were incubated with different concentrations of propofol $(0,5$, and $10 \mu \mathrm{M})$ for $24 \mathrm{~h}$. For cell transfection, miR-486 inhibitor was designed and produced by GenePharma (China). Cells without any vector transfection were considered the control group. Briefly, the cells $\left(2 \times 10^{4}\right.$ cells/per well $)$ were seeded on 96-well plates and incubated with or without propofol. Subsequently, the cells were then transiently transfected with miR-486 inhibitor according to the manufacturer's manual by using lipofectamine 2000 (Invitrogen, USA) for $48 \mathrm{~h}$. The cell suspension was collected for further analyses.

\section{Quantitative real-time polymerase chain reaction (qRT-PCR) analysis}

After $24 \mathrm{~h}$ of incubation with different concentrations of propofol, the cells were collected and washed with PBS. Total RNA was extracted from the cells using TRIzol reagent (Invitrogen) according to the manufacturer's protocol. Total RNA was reverse-transcribed and amplified with the Taqman MicroRNA Reverse Transcription kit (Applied Biosystems, USA) following the manufacturer's instructions. PCR reactions were carried out with Taqman 29 Universal PCR master mix (Applied Biosystems), with U6 snRNA as a loading control. The reverse transcription and primers were both acquired from Genepharma. All reactions were performed in triplicate and the data were analyzed by the ddCt method.

\section{Cell viability}

Cell viability was analyzed by 3-(4,5-dimethylthiazol2-yl)-2,5- diphenyltetrazolium bromide (MTT) colorimetric assay according to a standardized method (19). Briefly, the cells were inoculated into 96 -well plates, treated with propofol and transfected or not with miR-486 inhibitor. Forty-eight hours later, $20 \mu \mathrm{L} 5 \mathrm{mg} / \mathrm{mL}$ MTT (Gibco BRLLife Technologies, USA) was added to the plates and incubated at $37^{\circ} \mathrm{C}$ for $4 \mathrm{~h}$. The cells were then added with dimethylsulfoxide (DMSO; $100 \mu \mathrm{L}$; Sigma-Aldrich) to dissolve the formazan crystals. Absorbance was read at $590 \mathrm{~nm}$, determined with a microplate reader (Bio-Rad Benchmark, USA).

\section{Apoptosis assay}

Cell apoptosis was determined by an Annexin V/FITC and propidium iodide $(\mathrm{PI})$ apoptosis detection kit (Becton Dickinson, USA) according to the manufacturer's instructions. Briefly, $48 \mathrm{~h}$ after treatment and transfection, cells were collected and suspended in Annexin-binding buffer. The cells were then incubated with Annexin V-FITC and PI for $15 \mathrm{~min}$ in the dark at room temperature. Flow cytometry was performed to analyze the apoptotic percentage of cells.

\section{Western blot analysis}

After incubation and transfection, the cell suspension was harvested, centrifuged, and lysed in a lysis buffer. Total protein was extracted from the cells and measured using a BCA assay kit (Pierce, USA). After boiling for $10 \mathrm{~min}$, the protein samples were subjected to a $10-12 \%$ sodium dodecyl sulfate (SDS)-polyacrylamide gel electrophoresis (PAGE) and transferred to polyvinylidene fluoride (PVDF) membranes (Bio-Rad Benchmark). Subsequently, the cells were washed with phosphate buffer saline (PBS) and blocked with $5 \%$ skim milk in Tris buffered saline with tween (TBS-T) for $1 \mathrm{~h}$. The membranes were then maintained in the following primary antibodies overnight at $4^{\circ} \mathrm{C}$ : anti-FOXO1 antibody (ab52857, Abcam, UK), antiFOXO3 antibody (ab47285, Abcam), anti-Bcl-2 interacting mediator of cell death (Bim) antibody (ab32158, Abcam), anti-pro-caspase-3 antibody (ab32150, Abcam), and antiactive caspase- 3 antibody (ab2302, Abcam). Membranes were washed twice with TBS-T and then incubated with horseradish peroxidase-conjugated secondary antibodies for $2 \mathrm{~h}$. The protein bands were visualized with WESTZOL-plus Western Blot Detection System (Intron Biotechnology, Inc., Korea). Probing for GAPDH was used as a loading control.

\section{Statistical analysis}

All samples were run in triplicate. Data are reported as means \pm SD. GraphPad Prism 6 software (GraphPad, USA) was employed for statistical analyses. Statistical differences were assessed by paired $t$-tests or one-way analysis of variance (ANOVA). $\mathrm{P}<0.05$ was defined as statistically significant.

\section{Results}

\section{Propofol stimulated miR-486 expression}

As shown in Figure $1 \mathrm{~A}$, treatment with 5 or $10 \mu \mathrm{M}$ propofol significantly increased the levels of miR-486 in H1792 cells compared to the untreated cells $(\mathrm{P}<0.05$ or 

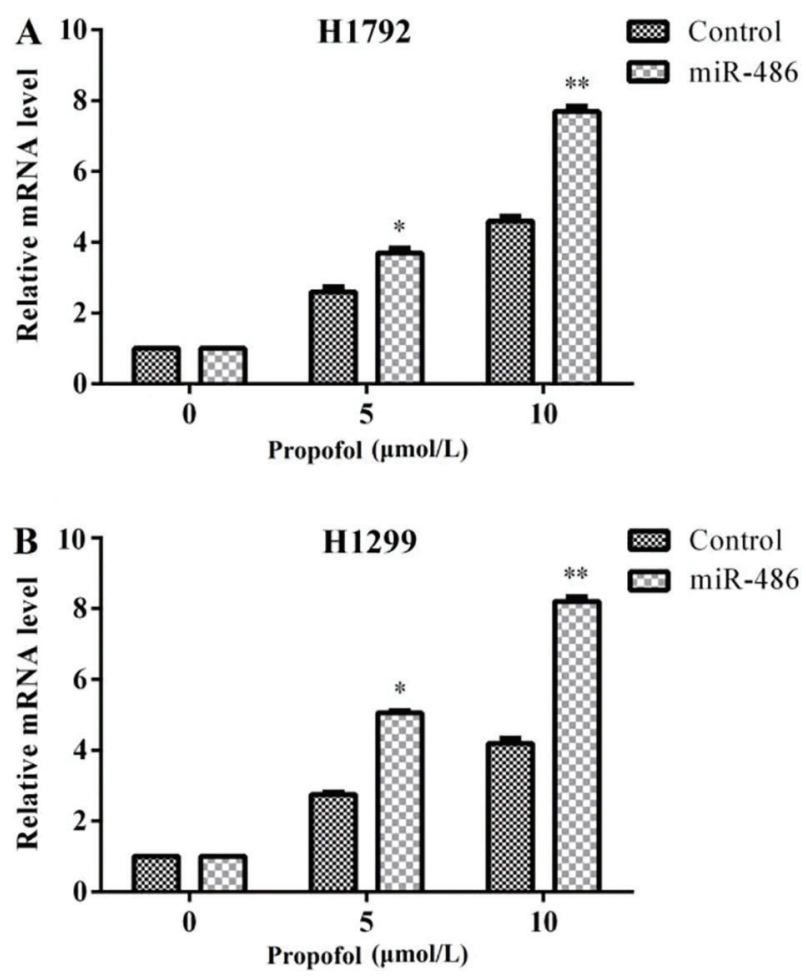

Figure 1. Lung cancer cell lines were treated or not with propofol for $24 \mathrm{~h}$, and the expression of miR-486 was determined by qRTPCR. Propofol significantly increased the levels of miR-486 in $\mathrm{H} 1792(A)$ and in $\mathrm{H} 1299(B)$ cells. Data are reported as mean $\pm \mathrm{SD}$. MiR: microRNA; qRT-PCR: quantitative real-time polymerase chain reaction. ${ }^{*} \mathrm{P}<0.05$ compared to the control group; ${ }^{* *} \mathrm{P}<0.01$ compared to the control group (t-test).

$\mathrm{P}<0.01$ ), in a concentration-dependent manner. Thus, we chose $10 \mu \mathrm{M}$ propofol for further analyzes. The expression pattern of miR-486 in H1299 cells showed similar results (Figure 1B). The results indicated that propofol could stimulate the expression of $\mathrm{miR}-486$.

\section{Suppression of $\mathrm{miR}-486$ reversed cell viability reduced by propofol in both $\mathrm{H} 1299$ and $\mathrm{H} 1792$ cells}

Lung cancer cell lines $\mathrm{H} 1792$ and $\mathrm{H} 1299$ cells were treated with or without $10 \mu \mathrm{M}$ propofol and transfected or not with miR-486 inhibitor. MTT was performed to determine the cell viability. The results showed that the cell viability in both $\mathrm{H} 1792$ and $\mathrm{H} 1299$ cells was significantly decreased by propofol compared to the control groups $(P<0.05)$. However, cell viability was significantly elevated by propofol combined with miR-486 inhibitor compared to the propofol group $(P<0.05)$. Further, the cell viability was dramatically higher by transfection with miR-486 compared to the propofol group or control group $(P<0.05$; Figure $2 A$ and $B)$. The results suggested that miR-486 suppression reversed the cell viability reduced by propofol.
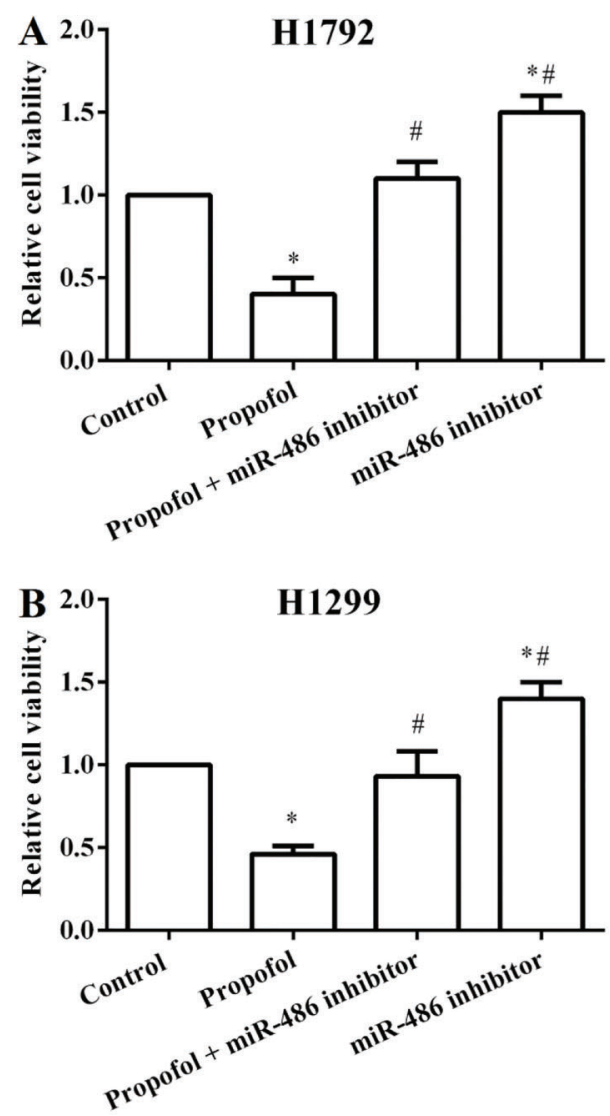

Figure 2. Relative cell viability in the different groups. Cell viability was significantly decreased by propofol, but these effects were reversed by transfection with miR-486 inhibitor in $\mathrm{H} 1792(A)$ and in $\mathrm{H} 1299(B)$ cells. Data are reported as mean \pm SD. MiR: microRNA. ${ }^{*} \mathrm{P}<0.05$ compared to the control group; ${ }^{\#} \mathrm{P}<0.05$ compared to the propofol group ( $t$-test).

\section{Suppression of miR-486 reversed cell apoptosis increased by propofol in $\mathrm{H} 1299$ cells}

As indicated in Figure $3 A$ and $B$, the percentages of apoptotic cells were significantly upregulated by administration of propofol compared to the control group $(\mathrm{P}<0.05)$ in $\mathrm{H} 1299$ cells. But the percentages of apoptotic cells were significantly downregulated by propofol combined with miR486 inhibitor compared to the propofol group $(P<0.05)$, whereas, the percentages of apoptotic cells were markedly increased by miR-486 inhibitor compared to the propofol group or control group $(P<0.05$ or $P<0.01)$. The results demonstrated that miR-486 suppression reversed the cell apoptosis increased by propofol.

\section{Propofol regulated cell viability and apoptosis by regulating miR-486/FOXO in $\mathrm{H} 1299$ cells}

As indicated in Figure 4, the expressions of FOXO1, FOXO3, Bim, pro- and activated caspase-3 were all significantly elevated by the administration of propofol 


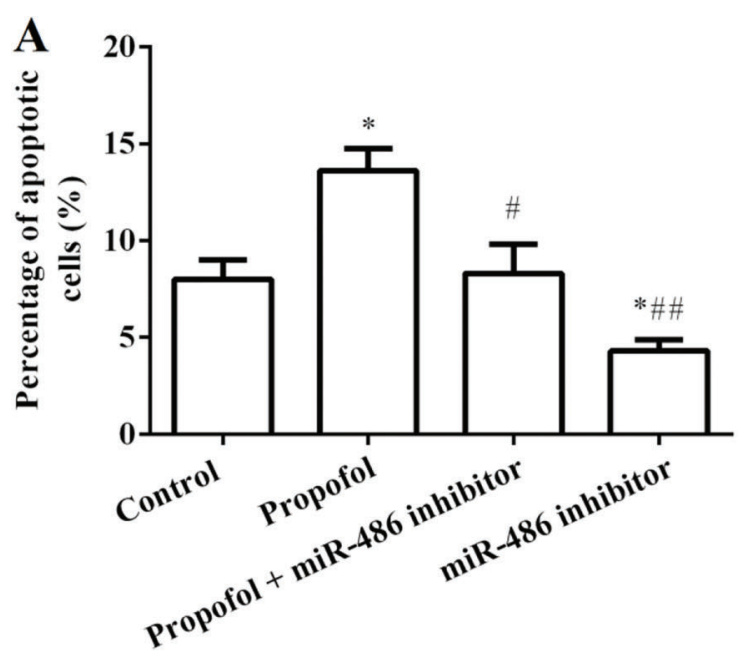

B
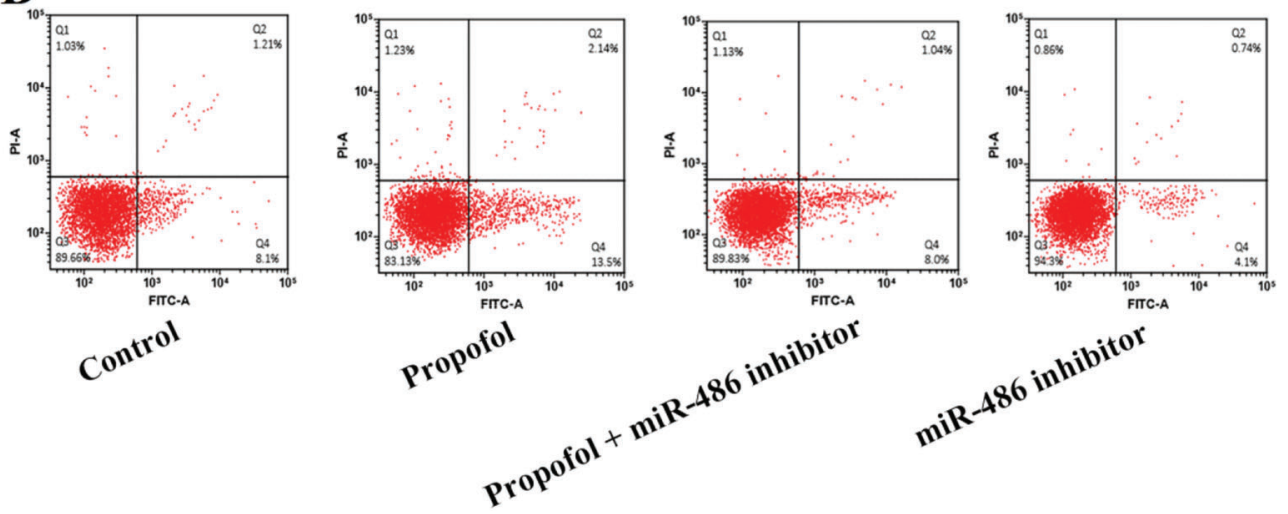

Figure 3. $A$, Percentages of apoptotic cells in the different groups measured by Annexin V/FITC and PI staining. Apoptotic cells were significantly increased by propofol, but these effects were reversed by transfection with miR-486 inhibitor in H1299 cells. $B$, Flow cytometry of cell apoptosis. Data are reported as mean $\pm \mathrm{SD}$. MiR: microRNA; PI: propidium iodide. ${ }^{*} \mathrm{P}<0.05$ compared to the control group; ${ }^{\#} \mathrm{P}<0.05$ compared to the propofol group; ${ }^{\#} \mathrm{P}<0.01$ compared to the propofol group ( $t$-test).

compared to the control group in H1299 cells, but were significantly decreased by miR-486 inhibitor. Moreover, the effects of propofol on these proteins were alleviated by simultaneous treatment with propofol and transfection with miR-486 inhibitor. These data demonstrated that propofol regulated $\mathrm{H} 1299$ cell viability and apoptosis by regulating miR-486/FOXO.

\section{Discussion}

Lung cancer is a major cause of mortality worldwide, and the clinical outcome is still poor in spite of early detection and treatment. Therefore, there is an urgent need to improve the current treatment or develop new therapeutic strategies. In the present study, we investigated the effects of propofol on the biological behavior of lung cancer cells and the role of miR-486 in these effects.
The results revealed that propofol could inhibit lung cancer cell viability and promote cell apoptosis. Besides, we observed that propofol stimulated the expression of miR-486, and suppression of miR-486 reversed the effects of propofol on lung cancer cell viability, apoptosis, and expression of apoptosis-related protein. Hence, our results suggest that propofol might be an ideal anesthetic for lung cancer surgery.

Anesthesia is a reliable method for reducing pain and is widely used during surgery. Numerous anesthetics have been reported to be used during cancer resection; however, the effects of these anesthetics on the behavior of cancer cells are uncertain (20). Propofol is a safe and an effective alternative for sedation. Some advantages, such as rapid onset and short duration of action, have been reported for propofol. Therefore, intravenous anesthesia with propofol is growing in popularity. Nevertheless it is noteworthy that, different concentrations of propofol reveal 


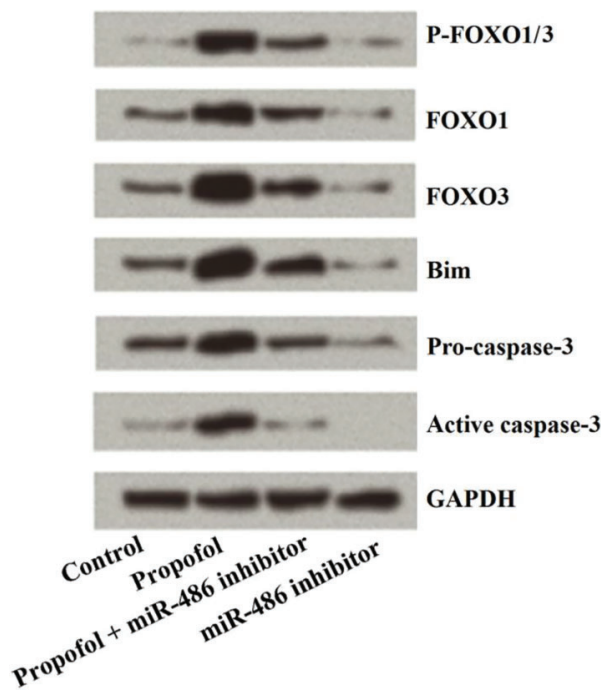

Figure 4. Western blot results for cell viability and apoptosis in H1299 cells, showing that the expressions of all evaluated proteins were significantly elevated by propofol, but these effects were reversed by transfection with miR-486 inhibitor in $\mathrm{H} 1299$ cells. MiR: microRNA; FOXO: forkhead box, class O; Bim: Bcl-2 interacting mediator of cell death.

contradictory results in different types of cancer cells. For example, Garib et al. (21) suggested that $34 \mu \mathrm{M}$ propofol significantly elevated the migration of MDA-MB-468 breast carcinoma cells. Conversely, Mammoto et al. (22) observed that $5.6-28 \mu \mathrm{M}$ propofol statistically reduced the invasion capacity of many human cancer cells including HeLa, HT1080, HOS and RPMI-7951. In addition, Miao et al. (23) demonstrated that $45 \mu \mathrm{M}$ propofol markedly inhibited the invasion ability of colon carcinoma cells. Thus, in the present study, a concentration range of propofol $(0-10 \mu \mathrm{M})$ was explored in respect to its effect on the behavior of lung cancer cell lines H1299 and H1792. In line with the above studies, our data also exhibited that administration of propofol inhibited cell viability and promoted cell apoptosis.

An increasing number of studies have revealed that propofol might regulate the biological behaviors of cancer cells by upregulating or downregulating the expression of miRNAs. For example, Su et al. (24) observed that propofol induced epithelial ovarian cancer cell apoptosis by upregulating the expression of miR-let-7i. Zhang et al. (25) suggested that propofol could effectively inhibit the adhesion of hepatocellular carcinoma ( $\mathrm{HCC}$ ) cells by upregulating miRNA-199a and downregulating metalloprotease-9 expression. Ye et al. (26) found that propofol inhibited the proliferation and invasion of osteosarcoma cells by the regulation of miR-143 expression. Wang et al. (17) demonstrated that propofol suppressed proliferation and invasion of pancreatic cancer cells by upregulating miR$133 a$ expression. Similarly, in the present study we revealed that propofol inhibited lung cancer cell viability and induced cell apoptosis by upregulating miR-486 expression. To elucidate the underlying mechanism involved in the inhibition of $\mathrm{H} 1299$ and $\mathrm{H} 1792$ cells, the effects of propofol on the expression of miR-486 was determined. We found that propofol could distinctly increase the levels of miR-486. More importantly, suppression of miR-486 by transfection with miR-486 inhibitor reversed the effects of propofol on lung cancer cells viability and apoptosis. These results indicated that the anti-tumor function of propofol might be partly due to the upregulation of miR-486.

The functional role of miR-486 in cancers has been extensively investigated. It has been demonstrated that miR-486 functions as a tumor-suppressor miRNA in many cancers such as breast cancer (27), HCC (28), and gastric cancer (29). Recently, studies have shown that miR-486 was downregulated in lung tumors compared with adjacent uninvolved lung tissues and that miR-486 might play an important role in the development of lung cancer $(12,13)$. In addition, miR-486 has been considered as a biomarker for early diagnosis and recurrence of non-small cell lung cancer (NSCLC) (30). To further explore the related mechanism underlying miR-486 suppression of cell viability and promotion of cell apoptosis, the expression of FOXO 1 and 3, Bim, and pro- and activated caspase- 3 was analyzed. It has been reported that FOXO transcription factors have the ability of regulating various cell functions such as cell proliferation, apoptosis, cell survival, metabolic processes, and DNA repair (31-33). FOXO is involved in cell growth and apoptosis by directly inducing the expression of FOXO3a-dependent apoptotic protein Bim $(34,35)$ and by activating caspase family (36). Moreover, FOXO stimulation could regulate specific gene expression, resulting in cell-cycle arrest, which implies that FOXO is responsible for the suppression of tumors (31). FOXO1 and FOXO3 (or FOXO3a) are two important members of FOXO family, which play critical roles in cell proliferation, cell cycle arrest and apoptosis $(31,37)$. A previous study showed that the expression of FOXO1 was a favorable prognostic factor in NSCLC (38). In addition, inactivation of FOXO3a occurs frequently in carcinogen-induced lung adenocarcinoma (39) and FOXO3a could regulate the cytotoxic effects of cisplatin in lung cancer cells (40). As indicated in our results, administration of propofol significantly increased the protein levels of FOXO1, FOXO3, Bim, pro-caspase-3 and activated caspase-3, while transfection with miR-486 inhibitor showed contrary results. Suppression of miR-486 reversed the effects of propofol on the expression of apoptosis-related protein.

In conclusion, our results suggest that propofol could effectively inhibit lung cancer cell viability and induce cell apoptosis, and that propofol might be an ideal anesthetic for lung cancer surgery. Modulation of miR-486 might contribute to the anti-tumor activity of propofol. 


\section{References}

1. Schwartz AG, Cote ML. Epidemiology of Lung Cancer. Adv Exp Med Biol 2016; 893: 21-41, doi: 10.1007/978-3-31924223-1.

2. Bittoni MA, Focht BC, Clinton SK, Buckworth J, Harris RE. Prospective evaluation of C-reactive protein, smoking and lung cancer death in the Third National Health and Nutrition Examination Survey. Int J Oncol 2015; 47: 1537-1544.

3. Stewart B, Wild CP. World cancer report 2014. International Agency for Research on Cancer. World Health Organization, 2014, 505

4. Hong QY, Wu GM, Qian GS, Hu CP, Zhou JY, Chen LA, et al. Prevention and management of lung cancer in China. Cancer 2015; 121(Suppl 17): 3080-3088, doi: 10.1002/cncr.29584.

5. Magasi S, Mallick R, Kaiser K, Patel JD, Lad T, Johnson ML, et al. Importance and relevance of pulmonary symptoms among patients receiving second- and third-line treatment for advanced non-small-cell lung cancer: support for the content validity of the 4-item Pulmonary Symptom Index. Clin Lung Cancer 2013; 14: 245-253, doi: 10.1016/j.cllc. 2012.07.001.

6. Bartel DP. MicroRNAs: target recognition and regulatory functions. Cell 2009; 136: 215-233, doi: 10.1016/j.cell.2009. 01.002.

7. Bartel DP. MicroRNAs: genomics, biogenesis, mechanism, and function. Cell 2004; 116: 281-297, doi: 10.1016/S00928674(04)00045-5.

8. Cheng CJ, Bahal R, Babar IA, Pincus Z, Barrera F, Liu C, et al. MicroRNA silencing for cancer therapy targeted to the tumour microenvironment. Nature 2015; 518: 107-110, doi: $10.1038 /$ nature13905.

9. Lin S, Gregory RI. MicroRNA biogenesis pathways in cancer. Nat Rev Cancer 2015; 15: 321-333, doi: 10.1038/ nrc3932.

10. MacDonagh L, Gray SG, Finn SP, Cuffe S, O’Byrne KJ, Barr MP. The emerging role of microRNAs in resistance to lung cancer treatments. Cancer Treat Rev 2015; 41: 160-169, doi: 10.1016/j.ctrv.2014.12.009.

11. Rusek AM, Abba M, Eljaszewicz A, Moniuszko M, Niklinski $\mathrm{J}$, Allgayer $\mathrm{H}$. MicroRNA modulators of epigenetic regulation, the tumor microenvironment and the immune system in lung cancer. Mol Cancer 2015; 14: 34, doi: 10.1186/s12943015-0302-8.

12. Wang J, Tian $X$, Han $R$, Zhang $X$, Wang $X$, Shen $H$, et al. Downregulation of miR-486-5p contributes to tumor progression and metastasis by targeting protumorigenic ARHGAP5 in lung cancer. Oncogene 2014; 33: 1181-1189, doi: 10.1038/onc.2013.42.

13. Peng Y, Dai Y, Hitchcock C, Yang X, Kassis ES, Liu L, et al. Insulin growth factor signaling is regulated by microRNA486, an underexpressed microRNA in lung cancer. Proc Natl Acad Sci U S A 2013; 110: 15043-15048, doi: 10.1073/ pnas. 1307107110.

14. Vasileiou I, Xanthos T, Koudouna E, Perrea D, Klonaris C, Katsargyris $A$, et al. Propofol: a review of its non-anaesthetic effects. Eur J Pharmacol 2009; 605: 1-8, doi: 10.1016/ j.ejphar.2009.01.007.
15. Zhang L, Wang N, Zhou S, Ye W, Jing G, Zhang M. Propofol induces proliferation and invasion of gallbladder cancer cells through activation of Nrf2. J Exp Clin Cancer Res 2012; 31: 66, doi: 10.1186/1756-9966-31-66.

16. Wang ZT, Gong HY, Zheng F, Liu DJ, Yue XQ. Propofol suppresses proliferation and invasion of gastric cancer cells via downregulation of microRNA-221 expression. Genet Mol Res 2015; 14: 8117-8124, doi: 10.4238/2015.July.17.20.

17. Wang ZT, Gong HY, Zheng F, Liu DJ, Dong TL. Propofol suppresses proliferation and invasion of pancreatic cancer cells by upregulating microRNA-133a expression. Genet Mol Res 2015; 14: 7529-7537, doi: 10.4238/2015.July.3.28.

18. Inada T, Kubo K, Shingu K. Possible link between cyclooxygenase-inhibiting and antitumor properties of propofol. $J$ Anesth 2011; 25: 569-575, doi: 10.1007/s00540-0111163-y.

19. Gerlier D, Thomasset N. Use of MTT colorimetric assay to measure cell activation. J Immunol Methods 1986; 94: 5763, doi: 10.1016/0022-1759(86)90215-2.

20. Santamaria LB, Schifilliti D, La Torre D, Fodale V. Drugs of anaesthesia and cancer. Surg Oncol 2010; 19: 63-81, doi: 10.1016/j.suronc.2009.03.007.

21. Garib V, Lang K, Niggemann B, Zanker KS, Brandt L, Dittmar T. Propofol-induced calcium signalling and actin reorganization within breast carcinoma cells. Eur J Anaesthesiol 2005; 22: 609-615, doi: 10.1017/S02650215050 0102X.

22. Mammoto T, Mukai M, Mammoto A, Yamanaka $Y$, Hayashi $Y$, Mashimo T, et al. Intravenous anesthetic, propofol inhibits invasion of cancer cells. Cancer Lett 2002; 184: 165-170, doi: 10.1016/S0304-3835(02)00210-0.

23. Miao $\mathrm{Y}$, Zhang $\mathrm{Y}$, Wan H, Chen L, Wang F. GABA-receptor agonist, propofol inhibits invasion of colon carcinoma cells. Biomed Pharmacother 2010; 64: 583-588, doi: 10.1016/ j.biopha.2010.03.006

24. Su Z, Hou XK, Wen QP. Propofol induces apoptosis of epithelial ovarian cancer cells by upregulation of microRNA let-7i expression. Eur J Gynaecol Oncol 2014; 35: 688-691.

25. Zhang J, Zhang D, Wu GQ, Feng ZY, Zhu SM. Propofol inhibits the adhesion of hepatocellular carcinoma cells by upregulating microRNA-199a and downregulating MMP-9 expression. Hepatobiliary Pancreat Dis Int 2013; 12: 305-309, doi: 10.1016/S1499-3872(13)60048-X.

26. Ye Z, Jingzhong L, Yangbo L, Lei $C$, Jiandong $Y$. Propofol inhibits proliferation and invasion of osteosarcoma cells by regulation of microRNA-143 expression. Oncol Res 2013; 21: 201-207, doi: 10.3727/096504014X13890370410203.

27. Zhang G, Liu Z, Cui G, Wang X, Yang Z. MicroRNA-486-5p targeting PIM-1 suppresses cell proliferation in breast cancer cells. Tumour Biol 2014; 35: 11137-11145, doi: 10.1007/ s13277-014-2412-0.

28. Huang $X P$, Hou J, Shen $X Y$, Huang $C Y$, Zhang $X H$, Xie YA, et al. MicroRNA-486-5p, which is downregulated in hepatocellular carcinoma, suppresses tumor growth by targeting PIK3R1. FEBS J 2015; 282: 579-594, doi: 10.1111/ febs.13167. 
29. Oh HK, Tan AL, Das K, Ooi CH, Deng NT, Tan IB, et al. Genomic loss of miR-486 regulates tumor progression and the OLFM4 antiapoptotic factor in gastric cancer. Clin Cancer Res 2011; 17: 2657-2667, doi: 10.1158/10780432.CCR-10-3152.

30. Li W, Wang Y, Zhang Q, Tang L, Liu X, Dai Y, et al. MicroRNA-486 as a Biomarker for Early Diagnosis and Recurrence of Non-Small Cell Lung Cancer. PLoS One 2015; 10: e0134220, doi: 10.1371/journal.pone.0134220.

31. Furukawa-Hibi $\mathrm{Y}$, Kobayashi $\mathrm{Y}$, Chen $\mathrm{C}$, Motoyama $\mathrm{N}$. FOXO transcription factors in cell-cycle regulation and the response to oxidative stress. Antioxid Redox Signal 2005; 7: 752-760, doi: 10.1089/ars.2005.7.752.

32. Paik JH, Kollipara R, Chu G, Ji H, Xiao Y, Ding Z, et al. FoxOs are lineage-restricted redundant tumor suppressors and regulate endothelial cell homeostasis. Cell 2007; 128: 309-323, doi: 10.1016/j.cell.2006.12.029.

33. Liu Z, Rudd MD, Hernandez-Gonzalez I, Gonzalez-Robayna I, Fan HY, Zeleznik AJ, et al. FSH and FOXO1 regulate genes in the sterol/steroid and lipid biosynthetic pathways in granulosa cells. Mol Endocrinol 2009; 23: 649-661, doi: 10.1210/me.2008-0412.

34. Gilley J, Coffer PJ, Ham J. FOXO transcription factors directly activate bim gene expression and promote apoptosis in sympathetic neurons. J Cell Biol 2003; 162: 613-622, doi: $10.1083 /$ jcb.200303026.
35. Stahl M, Dijkers PF, Kops GJ, Lens SM, Coffer PJ, Burgering $\mathrm{BM}$, et al. The forkhead transcription factor FoxO regulates transcription of $\mathrm{p} 27 \mathrm{Kip} 1$ and $\mathrm{Bim}$ in response to IL-2. J Immunol 2002; 168: 5024-5031, doi: 10.4049/ jimmunol.168.10.5024.

36. Brunet A, Bonni A, Zigmond MJ, Lin MZ, Juo P, Hu LS, et al. Akt promotes cell survival by phosphorylating and inhibiting a Forkhead transcription factor. Cell 1999; 96: 857-868, doi: 10.1016/S0092-8674(00)80595-4.

37. Wu Z, Sun H, Zeng W, He J, Mao X. Upregulation of MircoRNA-370 induces proliferation in human prostate cancer cells by downregulating the transcription factor FOXO1. PLoS One 2012; 7: e45825, doi: 10.1371/journal. pone.0045825.

38. Maekawa T, Maniwa $Y$, Doi T, Nishio $W$, Yoshimura M, Ohbayashi $\mathrm{C}$, et al. Expression and localization of FOXO1 in non-small cell lung cancer. Oncol Rep 2009; 22: 57-64.

39. Blake DC Jr, Mikse OR, Freeman WM, Herzog CR. FOXO3a elicits a pro-apoptotic transcription program and cellular response to human lung carcinogen nicotine-derived nitrosaminoketone (NNK). Lung Cancer 2010; 67: 37-47, doi: 10.1016/j.lungcan.2009.03.013.

40. Liu H, Yin J, Wang C, Gu Y, Deng M, He Z. FOXO3a mediates the cytotoxic effects of cisplatin in lung cancer cells. Anticancer Drugs 2014; 25: 898-907, doi: 10.1097/ CAD. 0000000000000117. 